\title{
Электрон-ядерное взаимодействия в X долине гетероструктур (In,Al)As/AlAs
}

\author{
Т.С. Шамирзаев ${ }^{1}$, М.С. Кузнецова ${ }^{2}$, К.В. Кавокин ${ }^{2}$, Д.С. Смирнов ${ }^{3}$, \\ J. Rautert ${ }^{4}$, Д.Р. Яковлев ${ }^{3,4}$, М. Bayer ${ }^{3,4}$ \\ ${ }^{1}$ ИФП СО РАН, 630090, Новосибирск, пр. Ак. Лаврентьева, 13 \\ ${ }^{2}$ Санкт-Петербургский государственный университет, 198504, Петергоф, ул. Ульяновская, д. 3. \\ ${ }^{3}$ ФТИ им. А.Ф.Иоффе, 19402 , С.-Петербург, ул. Политехническая 26. \\ ${ }^{4}$ TechnischeUniversität Dortmund, D-44221 Dortmund, Germany, Otto-Hahn-Strasse $4 a$
}

DOI 10.34077/RCSP2021-36

Экспериментально и теоретически изучалось сверхтонкое взаимодействие электронов и ядер в непрямозонных KT (In,Al)As/AlAs первого рода. Особенностью этих непрямозонных КТ является пренебрежимо малое анизотропное обменное взаимодействие электрона в $\mathrm{X}$ долине и дырки в $Г$ долине, что приводит к формированию экситонов, с «чистыми» спиновыми состояниями $\mid \pm 1>$, рекомбинирующих с излучением циркулярно-поляризованных фотонов. Для экспериментального определения электрон-ядерного взаимодействия измерялась циркулярная поляризация фотолюминесценции КТ в поперечном (эффект Ханле) и продольном (эффект восстановления циркулярной поляризации PRC) магнитных полях. Фотолюминесценция непрямо-зонных КТ возбуждалась квазирезонансно, через возбужденные состояния электрона, принадлежащие Г долине зоны проводимости циркулярно-поляризованым излучением Ti:Sapphire лазера.

$\mathrm{B}$ поперечном магнитном поле $(\mathrm{Bx})$ наблюдается эффект Ханле, т.е. степень циркулярной поляризации ФЛ уменьшается до нуля в полях несколько миллитесла. Контур Ханле описывается кривой Лоренца $\rho \mathrm{c}(\mathrm{Bx})=\rho 0 \mathrm{c} /\left(1+(\mathrm{Bx} / \Delta \mathrm{H})^{2}\right)$, где $\rho 0 \mathrm{c}-$ степень поляризации в нулевом поле, $\mathrm{c}$ половинной шириной на половинной интенсивности $\Delta \mathrm{H}=1.25$ мТл. В продольном магнитном поле степень циркулярной поляризации ФЛ увеличивается с ростом его напряженности. Кривая восстановления поляризации также описывается контуром Лоренца с шириной $\Delta \mathrm{RCP}$, совпадающей c $\Delta \mathrm{H}$.

Измерение температурных зависимостей ширин кривых Ханле и PRC в диапазоне температур 2$30 \mathrm{~K}$ показало, что их значения от температуры не зависят. Постоянство $\Delta \mathrm{RCP}$ и $\Delta \mathrm{H}$ в широком диапазоне температур позволяет сделать вывод о том, что при низких температурах спиновая релаксация спин-поляризованых электронов в КТ определяется сверхтонким взаимодействием со спинами ядер. Теоретический симметрийный анализ электронных блоховских амплитуд в $\mathrm{X}$ долине и микроскопический расчёт методом DFT показывают, что сверхтонкое взаимодействие в X долине, вопервых, подавлено по сравнению с Г долиной, а, во-вторых, анизотропно. Сравнение теории и DFT расчетов с экспериментальными данными дает возможность определить значения констант сверхтонкого взаимодействия для каждого и трех типов ядер (Al, In, As), формирующих КТ.

Работа выполнена при финансовой поддержке Deutsche Forschungsgemeinschaft via the Project No. 409810106 и РФФИ (проекты № 19-02-00098, 19-52-12001, 19-52-12043).

\section{Лumepamypa}

[1] J. Fischer et al., Phys. Rev.B, 78, 155329 (2008).

[2] T.S. Shamirzaev Phys.Solid State 60, 1554 (2018).

[3] A. V. Shchepetilnikov et al., Phys. Rev.B, 94, 241302(R) (2016). 